\title{
TO STUDY SERUM URIC ACID AS A RISK FACTOR IN ACUTE ISCHAEMIC STROKE
}

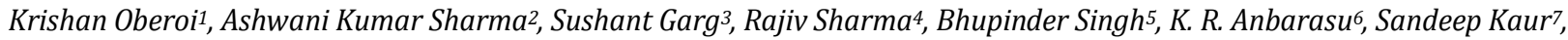 \\ Sunil Kumar ${ }^{8}$
}

\begin{abstract}
${ }^{1}$ Associate Professor, Department of General Medicine, Guru Nanak Dev Hospital, Amritsar. ${ }^{2}$ Associate Professor, Department of General Medicine, Guru Nanak Dev Hospital, Amritsar. 3Junior Resident, Department of General Medicine, Guru Nanak Dev Hospital, Amritsar. ${ }^{4}$ Assistant Professor, Department of General Medicine, Guru Nanak Dev Hospital, Amritsar. ${ }^{5}$ Assistant Professor, Department of General Medicine, Guru Nanak Dev Hospital, Amritsar. 6Junior Resident, Department of General Medicine, Guru Nanak Dev Hospital, Amritsar. 7Junior Resident, Department of General Medicine, Guru Nanak Dev Hospital, Amritsar. 8Junior Resident, Department of General Medicine, Guru Nanak Dev Hospital, Amritsar.
\end{abstract}

ABSTRACT
BACKGROUND
The objective of this study is to assess the association between serum uric acid and risk of stroke incidence and mortality along
with its correlation with other risk factors, because hyperuricaemia is hypothesised to be a risk factor for stroke, but to date results
from observational studies are conflicting.

\section{MATERIALS AND METHODS}

This prospective study was conducted on 60 patients of acute ischaemic stroke diagnosed on CT scan, admitted in Guru Nanak Dev Hospital attached to Govt. Medical College, Amritsar. Two groups were formed on the basis of serum uric acid levels and they are compared with respect to occurrence of stroke, risk factors and the prognosis at 1-month interval.

\section{RESULTS}

Out of 60 acute ischaemic stroke patients, 44 (73\%) patients had uric acid levels $\geq 5 \mathrm{mg} \%$. Highly significant association was found between serum uric acid and hypertension ( $p$ value 0.001). Similarly, significant correlation between serum uric acid and diabetes mellitus was found ( $p$ value 0.003 ). Correlation was also found between serum uric acid and dyslipidaemia ( $p$ value 0.03 ) in stroke patients. No correlation was found between serum uric acid and 1 month prognosis after stroke occurrence.

\section{CONCLUSION}

Elevated serum uric acid levels are strongly associated with risk of ischaemic stroke occurrence, but not with 1 month clinical outcome. There is a significant correlation between serum uric acid and stroke risk factors namely hypertension, diabetes mellitus and dyslipidaemia. Future research is needed to determine whether lowering uric acid level has any beneficial effects on stroke.

\section{KEYWORDS}

SUA, Serum Uric Acid, CVA, Stroke.

HOW TO CITE THIS ARTICLE: Oberoi K, Sharma AK, Garg S, et al. To study serum uric acid as a risk factor in acute ischaemic stroke. J. Evolution Med. Dent. Sci. 2017;6(8):647-652, DOI: 10.14260/Jemds/2017/139

\section{BACKGROUND}

Among all the neurological diseases of adult life, the cerebrovascular diseases clearly rank the first in frequency and importance. Stroke, after heart disease and cancer is the most common cause of death. In the developed countries among 700,000 cases of stroke, roughly 600,000 are ischaemic lesions. ${ }^{1}$ Stroke also entails a high socioeconomic burden due to increased morbidity and mortality. ${ }^{2}$ Ischaemic strokes account for $>80 \%$ of total stroke events. Early identification of individuals at risk could be of help in primary prevention strategies. ${ }^{3}$

A stroke or Cerebrovascular Accident (CVA) is defined by the abrupt onset of neurological deficit that is attributable to

Financial or Other, Competing Interest: None.

Submission 13-12-2016, Peer Review 12-01-2017,

Acceptance 19-01-2017, Published 25-01-2017.

Corresponding Author:

Dr. Sushant Garg,

Junior Resident,

Department of General Medicine Unit 5

Guru Nanak Dev Hospital, Amritsar.

E-mail: drsushantgarg@gmail.com

DOI: $10.14260 /$ jemds/2017/139

(c) (i) $\$$ a focal vascular cause. The clinical manifestations of stroke are highly variable, because of the complex anatomy of brain and its vasculature. Stroke should be considered in any patient presenting with an acute neurological deficit (focal or global) or altered level of consciousness. Patient symptoms vary depending on the area of the brain affected and the extent of the damage.

UA is long known to be most abundant aqueous antioxidant in humans by contributing to two-thirds of all free radical scavenging capacity in plasma. It is particularly effective in quenching hydroxyl, superoxide and peroxynitrite radicals and may serve a protective physiological role by preventing lipid peroxidation. ${ }^{4}$ It has been hypothesised that antioxidant properties of uric acid might be protective against aging, oxidative stress and oxidative injury of cardiac, vascular and neural cells. 5 However, as the findings of recent studies have unfolded, a new paradigm shift in the relationship between serum uric acid and health is emerging that antioxidant compounds may become pro-oxidant compounds in certain situations, particularly when they are present in blood at supranormal levels. 6

The role of Serum Uric Acid (SUA) levels as an independent risk factor for vascular disease has been 
questioned for decades. ${ }^{7}$ Evidence from epidemiological studies suggests that the elevated SUA levels may predict an increased risk for Cerebrovascular (CV) events including stroke.7-10 Moreover, therapeutic modalities with an SUA lowering potential have been shown to reduce CV disease morbidity and mortality. ${ }^{11}$

Subjects with NIDDM have a two-fold to four-fold greater risk of all manifestations of atherosclerotic vascular disease including stroke. ${ }^{9}$ The increased risk of stroke is only partly explained by the adverse effects of NIDDM on classic risk factors or risk factors clustering with hyperinsulinaemia. A study indicates that hyperuricaemia is a strong predictor of stroke events in middle-aged patients with NIDDM independent of other CV risk factors. ${ }^{9}$ SUA has been recently associated with insulin resistance. 12

In this respect, SUA levels could be used as an easy to measure serum marker in selecting and appropriately treating subjects at risk. ${ }^{12}$ Although, high SUA levels have been identified as an important risk factor for stroke in unselected populations in a number of epidemiological studies, $7-10$ it is unclear whether high SUA levels promote or protect against the development of Cardiovascular disease or simply acts as a passive or circumstantial marker of increased risk.13 However, data from larger studies (NHANES I) have established an independent association between serum uric acid and cardiovascular risk in subjects older than 45 years, regardless of confounding factors such as sex, menopausal status, diuretic use, presence of $\mathrm{CV}$ disease or race. ${ }^{8}$

\section{MATERIALS AND METHODS}

In this prospective study, 60 patients of acute ischaemic stroke diagnosed on CT scan who meet the criteria, attending the outpatient department as well as admitted in Guru Nanak Dev Hospital attached to Govt. Medical College, Amritsar were taken. Two groups were formed among the patients of acute ischaemic stroke based on their serum uric acid levels (Group A - Patients of acute ischaemic stroke with serum uric acid level $<5 \mathrm{mg} \%$ and Group B - Patients of acute ischaemic stroke with serum uric acid level $>5 \mathrm{mg} \%$ ). These groups were compared after collecting all the data with respect to occurrence of stroke, risk factors and the prognosis at 1month interval. The prognosis was assessed by the poor outcome at 1-month interval. The study was conducted after approval from Institutional Thesis and Ethical Committee. The purpose of study was explained to each individual and they were assured that the information were used for study purpose and were kept confidential with written consent and proforma. The blood samples were taken within 24 hours of onset of stroke and sent for uric acid estimation and other routine biochemical tests.

\section{Inclusion Criteria}

Patients with first-ever-in lifetime acute ischaemic stroke with CT evidence of infarction within 24 hours of onset of stroke.

\section{Exclusion Criteria}

1. Patients with previous history of TIA/CVA.

2. Patients on thiazide diuretics.
3. Known cases of gout.

4. Chronic renal failure patients.

5. Patients whose CT scan show haemorrhage or other space occupying lesions other than infarct.

6. Patients with haematological abnormalities like leukaemia or other myeloproliferative disorders.

\section{Clinical Examination and Investigations}

Detailed history and thorough general physical examination was done. Investigations were carried after detailed clinical evaluation in patients with features suggestive of stroke from the blood taken within 24 hours of stroke onset, i.e. Hb, TLC, DLC, blood sugar, blood urea, serum creatinine, lipid profile and serum uric acid. Other investigations included urine complete examination, ECG and NCCT Head. Uric acid in serum was measured by Uricase/PAP method as described by Fossati et al 1980.

\section{Followup}

The followup was done at 1-month interval after hospital discharge and prognosis was assessed by the poor outcome at 1-month interval. (Poor outcome - Score of more than 2 on modified Rankin Scale Score.

\section{Statistical Tools}

The information collected regarding all the selected cases was recorded in a Master Chart. Data analysis was done with the help of computer using software SPSS (Version 15). Using this software, frequencies, percentage, mean, standard deviation, $\mathrm{X}^{2}$ and ' $\mathrm{p}$ ' values were calculated. An attempt was made to correlate serum uric acid with stroke occurrence, prognosis and its other risk factors.

\section{RESULTS}

Our study was conducted on 60 stroke patients, of which males and females were almost equal in number (33 males and 27 females) and hence there was no sex bias. Mean age in males was 67.03 years and females 61.07 years. Distribution of risk factors also was more or less in similar pattern (Hypertension: males - 15, females - 14; Diabetes mellitus: males - 10, females - 14; Dyslipidaemia; males - 12, females - 10). This present study showed the statistically significant association of stroke risk with elevated serum uric acid done within 24 hours of acute ischaemic stroke; $73 \%$ of total stroke population was lying in Group B (Patients with serum uric acid level $\geq 5 \mathrm{mg} \%$ ) and $27 \%$ was lying in Group A (Patients with serum uric acid level $<5$ $\mathrm{mg} \%$ ). However, in elderly population both sexes showed high levels of SUA and the mean serum uric acid was seen to be in increasing trend with age. Regarding the association between risk factors and both sexes, hypertension was not seen to be significantly associated with high serum uric acid levels in both sexes, whereas Diabetes mellitus was seen to be associated significantly with males and not with females. In this study, most of the patients belonged to anterior circulation territory, especially of middle cerebral artery region with commonest presentation being hemiplegia. In this study, approximately $25 \%$ of the patients are above 70 yrs. with 10 males and 4 females. This study also showed evidences for a significant association between serum uric acid and elderly stroke population and the association was 
maintained even when both sexes were considered separately. Hypertension constituted the major risk factor as approximately $50 \%$ of the stroke population was hypertensive. The mean serum uric acid level of hypertensive patients was $6.29 \mathrm{mgs} / \mathrm{dL}$ as compared to nonhypertensive was $5.18 \mathrm{mgs} / \mathrm{dL}$ ( $\mathrm{p}$ value 0.001 ) and thus our study showed a statistically significant relationship between serum uric acid and hypertension in stroke population. Diabetes mellitus ranked second as a risk factor for stroke in this study constituting $40 \%$ of the study population. In this study also with the mean serum uric acid level of 6.25 $\mathrm{mg} / \mathrm{dL}$ among diabetics and $5.36 \mathrm{mg} / \mathrm{dL}$ among nondiabetics, there was a strong association between serum uric acid and diabetes mellitus. Further analysis showed that this association was stronger among males (mean serum uric acid in male diabetics - $6.40 \mathrm{mg} / \mathrm{dL}$ vs nondiabetic males $-5.35 \mathrm{mg} / \mathrm{dL}$ ) than females. Thus, our study strongly favoured for an association between serum uric acid and acute ischaemic stroke in diabetic population. In our study, dyslipidaemia was considered separately and not as a part of Metabolic syndrome. Moreover, most of the patients in this study population were from low socioeconomic group and were not found obese. In this study, the mean serum uric acid level in dyslipidaemic patients was $6.13 \mathrm{mgs} / \mathrm{dL}$ and in patients without dyslipidaemia was 5.48 $\mathrm{mgs} / \mathrm{dL}$ and showed a significant association between these variables. This study fails to show any statistically significant relationship of serum uric acid with alcoholism and smoking. Finally, our study also found no correlation between serum uric acid levels and 1-month clinical outcome.

\begin{tabular}{|l|c|c|c|}
\hline \multirow{2}{*}{ Risk Factors } & \multicolumn{2}{|c|}{$\begin{array}{c}\text { Mean Serum Uric } \\
\text { Acid (mg/dL) }\end{array}$} & \multirow{2}{*}{ P Value } \\
\cline { 2 - 3 } & Present & Absent & \\
\hline a) Hypertension & 6.29 & 5.18 & 0.001 \\
\hline b) Diabetes & 6.25 & 5.36 & 0.003 \\
\hline c) Dyslipidaemia & 6.03 & 5.48 & 0.03 \\
\hline d) Alcoholism & 5.50 & 5.66 & 0.623 \\
\hline e) Smoking & 5.825 & 5.703 & 0.786 \\
\hline \multicolumn{2}{|c|}{ Table 1. Correlation of Serum Uric Acid with } \\
various Risk Factors \\
\hline
\end{tabular}

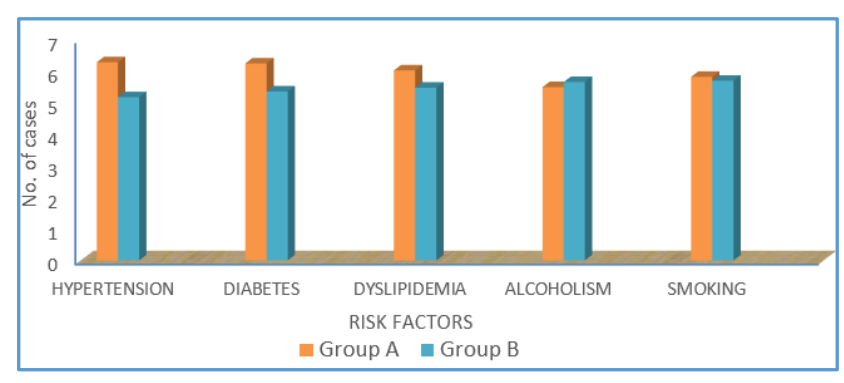

\begin{tabular}{|c|c|c|}
\hline Group & $\begin{array}{c}\text { No. of Stroke } \\
\text { Patients }\end{array}$ & \% Age \\
\hline A & 16 & 26.66 \\
\hline B & 44 & 73.34 \\
\hline Total & 60 & 100.0 \\
\hline P value & $<0.05$ & \\
\hline Table 2. Correlation of Serum Uric Acid with Stroke \\
\hline
\end{tabular}

\begin{tabular}{|c|c|c|c|c|}
\hline \multirow{3}{*}{ Risk Factors } & \multicolumn{4}{|c|}{ Serum Uric Acid } \\
\hline & \multicolumn{2}{|c|}{$\begin{array}{l}<5 \mathrm{mg} / \mathrm{dL} \\
\text { (Group A) }\end{array}$} & \multicolumn{2}{|c|}{$\begin{array}{c}>5 \mathrm{mg} / \mathrm{dL} \\
\text { (Group B) }\end{array}$} \\
\hline & No. & $\%$ & No. & $\%$ \\
\hline $\begin{array}{c}\text { a) Hypertension } \\
\text { Present } \\
\text { Absent }\end{array}$ & $\begin{array}{c}3 \\
13\end{array}$ & $\begin{array}{l}18.75 \\
81.25\end{array}$ & $\begin{array}{l}26 \\
18\end{array}$ & $\begin{array}{l}59.09 \\
40.91\end{array}$ \\
\hline $\mathrm{P}$ value & \multicolumn{4}{|c|}{0.006} \\
\hline $\begin{array}{c}\text { b) Diabetes } \\
\text { Present } \\
\text { Absent }\end{array}$ & $\begin{array}{c}4 \\
12\end{array}$ & $\begin{array}{l}25 \\
75\end{array}$ & $\begin{array}{l}20 \\
24\end{array}$ & $\begin{array}{l}45.45 \\
54.55\end{array}$ \\
\hline P value & \multicolumn{4}{|c|}{0.153} \\
\hline $\begin{array}{l}\text { c) Dyslipidaemia } \\
\text { Present } \\
\text { Absent }\end{array}$ & $\begin{array}{c}3 \\
13\end{array}$ & $\begin{array}{l}18.75 \\
81.25\end{array}$ & $\begin{array}{l}19 \\
25\end{array}$ & $\begin{array}{l}43.18 \\
56.82\end{array}$ \\
\hline P value & \multicolumn{4}{|c|}{0.082} \\
\hline $\begin{array}{c}\text { d) Alcoholism } \\
\text { Yes } \\
\text { No } \\
\end{array}$ & $\begin{array}{c}4 \\
12 \\
\end{array}$ & $\begin{array}{l}25 \\
75 \\
\end{array}$ & $\begin{array}{l}13 \\
31 \\
\end{array}$ & $\begin{array}{l}29.54 \\
70.46 \\
\end{array}$ \\
\hline P value & \multicolumn{4}{|c|}{0.730} \\
\hline $\begin{array}{c}\text { e) Smoking } \\
\text { Yes } \\
\text { No }\end{array}$ & $\begin{array}{c}2 \\
14\end{array}$ & $\begin{array}{l}12.5 \\
87.5\end{array}$ & $\begin{array}{c}6 \\
38\end{array}$ & $\begin{array}{l}13.63 \\
86.37\end{array}$ \\
\hline $\mathrm{P}$ value & \multicolumn{4}{|c|}{0.909} \\
\hline $\begin{array}{l}\text { Table 3. Correl } \\
\text { Acid in Strok }\end{array}$ & 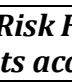 & $r s w$ & ISe & Uric \\
\hline
\end{tabular}

\begin{tabular}{|c|c|c|c|c|}
\hline \multirow{3}{*}{ Outcome } & \multicolumn{4}{|c|}{ Serum Uric Acid } \\
\cline { 2 - 5 } & $\begin{array}{c}<\mathbf{5 ~ m g / d L} \\
\text { (Group A) }\end{array}$ & $\begin{array}{c}\text { > 5 mg/dL } \\
\text { (Group B) }\end{array}$ \\
\cline { 2 - 5 } & No. & $\mathbf{\%}$ & No. & $\%$ \\
\hline Good Outcome (mRS < 2) & 4 & 25.0 & 8 & 18.18 \\
\hline Poor Outcome (mRS > 3) & 12 & 75.0 & 36 & 81.82 \\
\hline P value & \multicolumn{4}{|c|}{0.559} \\
\hline Table 4. Correlation of Patient Outcome after Stroke \\
with Serum Uric Acid \\
\hline
\end{tabular}

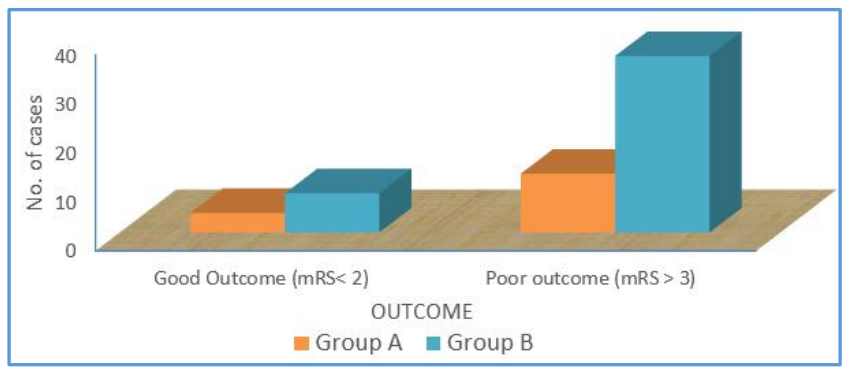

\section{DISCUSSION}

Stroke is defined by abrupt onset of neurological deficit that is attributable to focal vascular cause. Worldwide about 20 million people suffer from stroke each year; 5 million will die as a consequence; of those who survive, 5 million will be disabled by stroke. The Global Burden of Disease (GBD) study in 1990 reported 9.4 million deaths in India, of which 
61,900 were from stroke. India will face an enormous socioeconomic burden to meet the costs of rehabilitation of "stroke victims," because the population is surviving through the peak years ( 55 years to 65 years) of occurrence of stroke. In India, community surveys have shown a crude prevalence rate for hemiplegia in the range of 220 per 100,000 persons.

Serum uric acid is one of the major aqueous antioxidant in human beings and constitutes as much as $2 / 3^{\text {rd }}$ of plasma free radical scavenging ability. It is therefore prudent to expect that serum uric acid should have a protective role in stroke. But only few studies ${ }^{14}$ have found that higher levels of serum uric acid being neuroprotective in patients with stroke. An explanation to this comes from study, which showed that serum uric acid can work as pro-oxidant under certain circumstances, particularly if the levels of other antioxidants like ascorbic acid are low. ${ }^{15}$ Various studies have shown that serum uric acid can result in endothelial dysfunction, which can lead to vascular disease. An association between serum uric acid and inflammatory markers has also been discovered. 16

According to Hayden et al, ${ }^{17}$ serum uric acid acts like an antioxidant in the early stages of atherosclerotic process, being one of the most powerful determinant of plasma antioxidant capacity. Later, in the evolution of atherosclerotic process when serum uric acid reaches 4-6 $\mathrm{mg} / \mathrm{dL}$ it becomes pro-oxidant. The antioxidant pro-oxidant urate shuttle relies on its surrounding environment. Cerebral ischaemia initiates a complex cascade of metabolic events generating nitric oxide and free oxygen radicals.

Our present study was conducted on 60 stroke patients, of which males and females were almost equal in number (33 males and 27 females) and hence there was no sex bias. Mean age in males was 67.03 years and female was 61.07 years. Distribution of risk factors also was more or less similar in pattern (Hypertension: males - 15, females - 14; Diabetes mellitus: males - 10, females - 14; Dyslipidaemia: males - 12, females - 10). Milionis et al found high levels of serum uric acid in males, which was not seen in our study. ${ }^{18}$ Our study showed mean serum uric acid of $5.66 \mathrm{mg} / \mathrm{dL}$ in males and $5.78 \mathrm{mg} / \mathrm{dL}$ in females.

This present study showed the statistically significant association of stroke risk with elevated serum uric acid done within 24 hours of acute ischaemic stroke; $73 \%$ of total stroke population was lying in Group B (patients with serum uric acid level $>5 \mathrm{mg} \%$ ) and $27 \%$ lies in Group A (patients with serum uric acid level $<5 \mathrm{mg} \%$ ).

However, in elderly population both sexes showed high levels of serum uric acid and the mean serum uric acid was seen to be in increasing trend with age. Our study was consistent with Milionis et al, who found elevated serum uric acid in individuals older than 70 years. ${ }^{18}$ Regarding the association between risk factors and both sexes, hypertension was not seen to be significantly associated with high serum uric acid levels in both sexes, whereas diabetes mellitus was seen to be associated significantly with males and not with females.

In our present study, most of the patients belonged to anterior circulation territory, especially of middle cerebral artery region with commonest presentation being hemiplegia.
Age is the most common non-modifiable risk factor for the development of stroke. ${ }^{12}$ In our study, approximately $25 \%$ of the patients were above 70 years with 10 males and 4 females. Milionis et al ${ }^{18}$ studied 163 patients for association of serum uric acid and stroke concluded that serum uric acid is associated with an increased risk for acute ischaemic/non-embolic stroke in elderly patients independently of concurrent metabolic derangements. Our present study also showed evidences for a significant association between serum uric acid and elderly stroke population and the association was maintained even when both sexes were considered separately.

Elevated serum uric acid level is an independent predictor of hypertension in $25 \%$ of patients with new-onset untreated primary hypertension. ${ }^{19}$ In our present study, hypertension constituted the major risk factor as approximately $50 \%$ of the stroke population was hypertensive. The mean serum uric acid level of hypertensive patients was $6.29 \mathrm{mgs} / \mathrm{dL}$ and of nonhypertensive was $5.18 \mathrm{mgs} / \mathrm{dL}$ and thus our study showed a statistically significant relationship between serum uric acid and hypertension in stroke patients.

Diabetes mellitus ranks second as a risk factor for stroke in this study, constituting $40 \%$ of the study population. A study done by Lehto $\mathrm{S}$ et $\mathrm{al}^{9}$ involving 1017 persons with NIDDM concluded that hyperuricaemia is a strong predictor of stroke events in middle-aged persons with NIDDM, independently of other CV risk factors. According to studies done by Cook et $\mathrm{al}^{20}$ and Kuo-Liong Chien et al,21 diabetes has been associated with increased serum uric acid levels. In this study also with the mean serum uric acid level of 6.25 $\mathrm{mgs} / \mathrm{dL}$ among diabetics and $5.36 \mathrm{mgs} / \mathrm{dL}$ among nondiabetics, there was a strong association between serum uric acid and diabetes mellitus. Further analysis showed that this association was stronger among males (Mean serum uric acid in male diabetics - $6.40 \mathrm{mg} / \mathrm{dL}$ vs non-diabetic males - $5.35 \mathrm{mg} / \mathrm{dL}$ ) than females. Thus, this study strongly favoured for an association between serum uric acid and acute ischaemic/non-embolic stroke in diabetic population.

Several prospective studies ${ }^{22}$ have shown that higher levels of total cholesterol increase the risk of ischaemic stroke. Amerenco P et $\mathrm{al}^{23}$ conducted a meta-analysis of 90,000 patients showed that administration of statins reduces the risk of stroke among patients with CAD and that this risk reduction is primarily related to the extent to which LDL-C levels are lowered. In some studies ${ }^{24}$ relating metabolic syndrome and serum uric acid, increased serum uric acid levels correlated with low HDL-C levels. In our study, dyslipidaemia was considered separately and not as a part of metabolic syndrome. Moreover, most of the patients in our study population were from low socio-economic group and were not found obese. In this study, the mean serum uric acid level in dyslipidaemic patients was 6.13 $\mathrm{mgs} / \mathrm{dL}$ and in patients without dyslipidaemia was 5.48 $\mathrm{mgs} / \mathrm{dL}$ and showed a significant association between these variables. This result was consistent with study by KL Chien et al, ${ }^{21}$ which showed significant association of low density lipoproteins with raised serum uric acid in stroke population.

Among the other risk factors like smoking and alcoholism, they are not considered as separate risk factors in many pilot studies of this kind. This study also fails to 
show any statistically significant relationship between serum uric acid and these risk factors when considered separately.

Several studies have provided conflicting results about the prognostic significance of raised serum uric acid in stroke. Study done by Chiquete et $\mathrm{al}^{25}$ showed improved 30day clinical outcome in patients with serum uric acid $<4.5$ $\mathrm{mg} / \mathrm{dL}$ (outcome assessed by Modified Rankin Scale). A cohort study by Newman et $\mathrm{al}^{26}$ in 2006 on 140 patients also concluded that elevated serum uric acid is significantly and independently associated with increased risk of future vascular events in diabetic stroke population. Asterios et al 27 in 2007 also concluded that elevated levels of serum uric acid are associated with increased risk of early death in stroke. In contrast to above three studies, a study was done by Bin Zhang et $\mathrm{al}^{28}$ in year 2010 , which concluded that elevated serum uric acid is an independent predictor for good clinical outcomes of acute cerebral infarction among young adults. Similarly, lower serum uric acid levels independently predicted poor functional outcomes at 1-year interval after acute ischaemic stroke.

Also, some recent studies including study by Seet et al $^{29}$ in year 2010 and study by Miedema et $\mathrm{al}^{30}$ in 2012 found no association of serum uric acid with short and long outcomes in acute ischaemic stroke. Our present study also found no correlation of elevated serum uric acid concentrations with clinical outcome at 1-month interval after stroke. Further analysis between $<5 \mathrm{mgs} / \mathrm{dL}$ and $>5 \mathrm{mgs} / \mathrm{dL}$ serum uric acid groups also maintain the association between high serum uric acid and the risk factor, i.e. hypertension.

\section{REFERENCES}

[1] Ropper A, Samuels M, Klein J. Adam and Victor's principles of neurology. $8^{\text {th }}$ edn. Ch. 34. New York: McGraw Hill Professional; 2014:660-9.

[2] Bonita R. Epidemiology of stroke. Lancet 1992;339(8789):342-4.

[3] Buckley BM. Healthy ageing: ageing safely. Eur Heart J 2001;3 Suppl N:N6-10.

[4] Squadrito GL, Cueto R, Splenser AE, et al. Reaction of uric acid with peroxynitrite and implications for the mechanism of neuroprotection by uric acid. Archives of Biochemistry and Biophysics 2000;376(2):333-7.

[5] Glantzounis GK, Tsimoyiannis EC, Kappas AM, et al. Uric acid and oxidative stress. Curr Pharm Des 2005;11(32):4145-51.

[6] Bagnati M, Perugini C, Cau C, et al. When and why a water-soluble antioxidant becomes pro-oxidant during copper-induced low-density lipoprotein oxidation: a study using uric acid. Biochemical Journal 1999;340(Pt 1):143-52.

[7] Daskalopoulou SS, Athyros VG, Elisaf M, et al. Uric acid levels and vascular disease. Current Medical Research and Opinion 2004;20(6):951-4.

[8] Fang J, Alderman MH. Serum uric acid and cardiovascular mortality: the NHANES I epidemiologic follow-up study, 1971-1992. JAMA 2000;283(18):2404-10.
[9] Lehto S, Niskanen L, Rönnemaa T, et al. Serum uric acid is a strong predictor of stroke in patients with non-insulin-dependent diabetes mellitus. Stroke 1998;29(3):635-9.

[10] Weir CJ, Muir SW, Walters MR, et al. Serum urate as an independent predictor of poor outcome and future vascular events after acute stroke. Stroke 2003;34(8):1951-6.

[11] Høieggen A, Alderman MH, Kjeldsen SE, et al. The impact of serum uric acid on cardiovascular outcomes in the LIFE study. Kidney International 2004;65(3):1041-9.

[12] Rathmann W, Funkhouser E, Dyer AR, et al. Relations of hyperuricemia with the various components of the insulin resistance syndrome in young black and white adults: the CARDIA study. Coronary artery risk development in young adults. Ann Epidemiol 1998;8(4):250-61.

[13] Waring WS. Uric acid: an important antioxidant in acute ischaemic stroke. QJM 2002;95(10):691-3.

[14] Chamorro Á, Obach V, Cervera Á, et al. Prognostic significance of uric acid serum concentration in patients with acute ischemic stroke. Stroke 2002;33(4):1048-52.

[15] Abuja PM. Ascorbate prevents prooxidant effects of urate in oxidation of human low density lipoprotein. FEBS Lett 1999;446(2-3):305-8.

[16] Waring WS, Webb DJ, Maxwell SR. Effect of local hyperuricemia on endothelial function in the human forearm vascular bed. $\mathrm{Br} \mathrm{J}$ Clin Pharmacol 2000;49(5):511.

[17] Hayden MR, Tyagi SC. Uric acid: a new look at an old risk marker for cardiovascular disease, metabolic syndrome, and type 2 diabetes mellitus: the urate redox shuttle. Nutrition \& Metabolism 2004;1(1):10.

[18] Milionis HJ, Kalantzi KJ, Goudevenos JA, et al. Serum uric acid levels and risk for acute ischaemic nonembolic stroke in elderly subjects. J Intern Med 2005;258(5):435-41.

[19] Cannon PJ, Stason WB, Demartini FE, et al. Hyperuricemia in primary and renal hypertension. New England Journal of Medicine 1966;275(9):45764.

[20] Cook DG, Shaper AG, Thelle DS, et al. Serum uric acid, serum glucose and diabetes: relationships in a population study. Postgrad Med J 1986;62(733):1001-6.

[21] Chien KL, Hsu HC, Sung FC, et al. Hyperuricemia as a risk factor on cardiovascular events in Taiwan: the Chin-Shan community cardiovascular cohort study. Atherosclerosis 2005;183(1):147-55.

[22] Zhang X, Patel A, Horibe $\mathrm{H}$, et al. Cholesterol, coronary heart disease, and stroke in the Asia-Pacific region. Int J Epidemiol 2003;32(4):563-72.

[23] Amarenco P, Labreuche J, Lavallée P, et al. Statins in stroke prevention and carotid atherosclerosis: systematic review and up-to-date meta-analysis. Stroke 2004;35(12):2902-9.

[24] Yoo TW, Sung KC, Shin HS, et al. Relationship between serum uric acid concentration and insulin resistance and metabolic syndrome. Circ J 2005;69(8):928-33. 
[25] Chiquete E, Ruiz-Sandoval JL, Murillo-Bonilla LM, et al. Serum uric acid and outcome after acute ischemic stroke: PREMIER study. Cerebrovasc Dis 2013;35(2):168-74.

[26] Newman EJ, Rahman FS, Lees KR, et al. Elevated serum urate concentration independently predicts poor outcome following stroke in patients with diabetes. Diabetes Metab Res Rev 2006;22(1):79-82.

[27] Karagiannis A, Mikhailidis DP, Tziomalos K, et al. Serum uric acid as an independent predictor of early death after acute stroke. Circ J 2007;71(7):1120-7.
[28] Zhang B, Gao C, Yang N, et al. Is elevated SUA associated with worse outcome in young Chinese patients with acute cerebral ischemic stroke? BMC Neurol 2010;10:82.

[29] Seet RC, Kasiman K, Gruber J, et al. Is uric acid protective or deleterious in acute ischemic stroke? A prospective cohort study. Atherosclerosis 2010;209(1):215-9.

[30] Miedema I, Uyttenboogaart M, Koch M, et al. Lack of association between serum uric acid levels and outcome in acute ischemic stroke. J Neurol Sci 2012;319(1-2):51-5. 